\title{
Soot emitted from domestic stoves during solid fuel combustion
}

\author{
M. MICHALIK ${ }^{1 *}$, W. DRZEWICKI ${ }^{2}$, R. JANUS $^{3,4}$, M.
} WĄDRZYK $^{3,4}$, W. WILCZYŃSKA-MICHALIK ${ }^{5}$, N. ZIOŁA ${ }^{6}$

${ }^{1}$ Jagiellonian University, Institute of Geological Sciences, Krakow, Poland (*correspondence: marek.michalik@uj.edu.pl)

${ }^{2}$ University of Wrocław, Institute of Geological Sciences Wroclaw, Poland (wojciech.drzewicki@uwr.edu.pl)

${ }^{3}$ AGH University of Science and Technology, Faculty of Energy and Fuels, Krakow, Poland

${ }^{4}$ AGH University of Science and Technology, AGH Centre of Energy (rjanus@agh.edu.pl,wadrzyk@agh.edu.pl)

${ }^{5}$ Pedagogical University, Institute of Geography, Kraków, Poland (wanda.wilczynska-michalik@up.krakow.pl)

${ }^{6}$ University of Silesia, Faculty of Natural Sciences, Sosnowiec, Poland (natalia.ziola@vp.pl)

Soot emitted to atmosphere acts as important factor of global warming and impacts strongly human health.

Soot samples collected from domestic heating systems were studied. A studied material is composed of small (ca. $100 \mathrm{~nm}$ ) carbonaceous particles forming agglomerates. Interpretation of Raman spectra indicates that soot samples differ in the degree of ordering. Different degree of ordering was also noted for domains within one sample. The ATR-FTIR study of soot revealed the presence of aliphatic and aromatic $\mathrm{C}-\mathrm{H}$ groups as well as various oxygen-containing organic moieties, i.e. $\mathrm{C}=\mathrm{O}, \mathrm{C}-\mathrm{O}-\mathrm{C}$, and $-\mathrm{C}-\mathrm{OH}$. Besides, the characteristic absorption bands at ca. 1625 and $3419 \mathrm{~cm}^{-1}$ indicate the abundant amount of physically adsorbed water related to mineral matter.

Non carbonaceous matter, present as irregular forms or speherical particles, was studied using SEM-EDS method. Dominant mineral components determined using XRD are: salammoniac, quartz, arkanite, mascagnite, anhydrite, bassanite. $\delta^{13} \mathrm{C}$ values varies from -22.37 to $-32.60 \%$ o (average -24.80\%o). Content of different chemical elements in soot varies within broad range, e.g.: As from 707 to $<0.1$ ppm; Pb from 20434 to $53 \mathrm{ppm}$; Se from 100 to $0.3 \mathrm{ppm}$; $\mathrm{Zn}$ from 7392 to $233 \mathrm{ppm}$; Hg from 15443 to $19 \mathrm{ppb}$. Content of elements in water leachates is also variable, e.g.: As from 2160 to $41 \mu \mathrm{g} / \mathrm{L} ; \mathrm{F}$ from 4.3 to $3.6 \mathrm{mg} / \mathrm{L}$; $\mathrm{Cl}$ from 373 to 79 $\mathrm{mg} / \mathrm{L}$.

Acknowledgements. Research was supported within subsidy of Ministry of Science and Higher Education (statutory tasks) to Universities listed in affiliations. The research was partially carried out using the infrastructure of the AGH Centre of Energy, AGH University of Science and Technology. 